Portland State University

PDXScholar

6-8-2016

\title{
Mimicking the Bioactivation of the Antitubercular Agent Ethionamide using Peracetic Acid
}

Isabelle E. Logan

Portland State University

Follow this and additional works at: https://pdxscholar.library.pdx.edu/honorstheses

Let us know how access to this document benefits you.

\section{Recommended Citation}

Logan, Isabelle E., "Mimicking the Bioactivation of the Antitubercular Agent Ethionamide using Peracetic Acid" (2016). University Honors Theses. Paper 272.

https://doi.org/10.15760/honors.234

This Thesis is brought to you for free and open access. It has been accepted for inclusion in University Honors Theses by an authorized administrator of PDXScholar. Please contact us if we can make this document more accessible: pdxscholar@pdx.edu. 
Mimicking the Bioactivation of the Antitubercular Agent Ethionamide using Peracetic Acid

by

Isabelle E. Logan

An undergraduate honors thesis submitted in partial fulfillment of the

requirements for the degree of

Bachelor of Science

in

University Honors

and

Biochemistry

Thesis Adviser

Dr. Reuben H. Simoyi

Portland State University

2016 


\begin{abstract}
Tuberculosis still affects a large number of the world's population and drug resistance is becoming an increasing problem. Second line of defense antitubercular agents such as ethionamide (ETD) are thus becoming increasingly important. Since ethionamide is a prodrug, its metabolization through oxidation by a monooxygenase was successfully mimicked using peracetic acid. The reaction was found to be biphasic, with a fast initial oxidation to yield ethionamide sulfoxide (ETD-SO), which was relatively stable and was successfully isolated. We derived a bimolecular rate constant of $3.08 \pm 0.72 \times 10^{2} \mathrm{M}^{-1} \mathrm{~s}^{-1}$ for this initial phase of the reaction. In the slow second phase, further oxidation yielded 2-ethylisonicotinamide, where zero order kinetics were observed. Electrospray ionization mass spectroscopy (ESI-MS) was used to determine the identities of the products. No sulfinic nor sulfonic acids were detected, indicating that the sulfur-carbon bond was cleaved at the sulfenic acid stage, resulting in the release of an unstable sulfur monoxide species, which dimerized in solution to form dithionite.
\end{abstract}




\section{INTRODUCTION}

When asked about tuberculosis, many people living in the United States today might assume that tuberculosis was eradicated. However, in 2014 alone, 9.6 million people fell ill with tuberculosis and 1.5 million perished due to the disease. ${ }^{1}$ This information shows that tuberculosis is still a wide-spread disease. While the number of cases reported in the United States has been decreasing annually from a peak in 1992, in 2014 over nine thousand cases were reported. $^{2}$

Tuberculosis is effectively treated with antibiotics and significant efforts have been devoted to shedding light onto both the offensive and defensive mechanisms employed by the bacterium that causes the disease, Mycobacterium tuberculosis. How the antibiotics block those

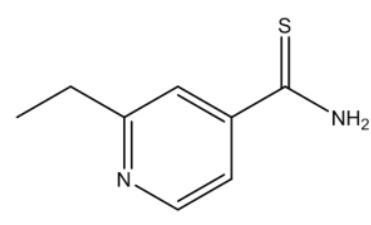

Figure 1. Ethionamide mechanisms, and the exact identities of most of these mechanisms are still rather elusive. ${ }^{3}$ However, thiosemicarbazones such as ethionamide, of which the structure is shown in Figure 1, have been found to inhibit cell wall biosynthesis. ${ }^{4}$

Drug resistance is an increasing problem faced in the treatment of tuberculosis. The World Health Organization (WHO) estimated that $4.3 \%$ of new and previously treated cases of tuberculosis now face a multidrug resistant bacterium, which is resistant to the most popular drugs, isoniazid and rifampicin. ${ }^{5}$ Second line of defense drugs such as capreomycin and ethionamide are thus becoming more important in treatment. ${ }^{6}$

Therefore, it is important to study these antibiotics, specifically, to perform kinetic and mechanistic studies that reveal what products are formed as an antibiotic such as ethionamide is metabolized in the human body. It has been shown that ethionamide is oxidized inside the 
bacterium to a 4-pyridylmethanol product via a sulfoxide intermediate. ${ }^{7}$ One possible pathway to mimic this metabolization is oxidation by peracetic acid, as was proven to be successful in the oxidation of thionicotinamide, which is structurally similar to ethionamide. ${ }^{8}$ Since ethionamide is taken orally, metabolism will also occur inside liver cells and the identification of these metabolites is vital in understanding the liver toxicity of the drug.

Ethionamide is a yellow powder and thus absorbs in the visible region of the spectrum. It was proposed that as ethionamide is oxidized, there may be a shift in its absorption spectrum. This enables the use of Ultraviolet-visible spectroscopy (UV/Vis) in order to follow the depletion of ethionamide as the oxidation occurs.

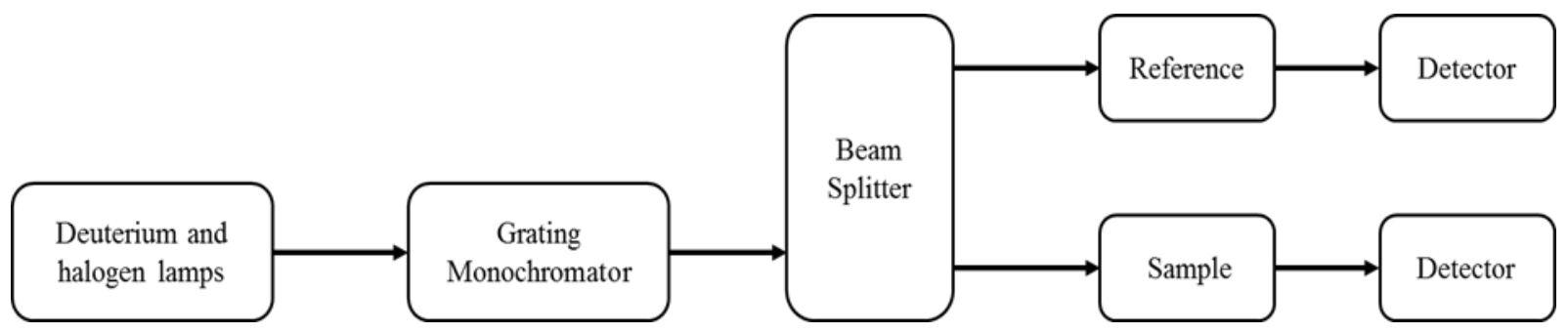

Figure 2. Block diagram of UV/Vis instrument

A block diagram of the UV/Vis spectrophotometer is shown in Figure 2, and it shows that the instrument houses two lamps, a deuterium lamp for the ultraviolet region and a halogen lamp for the visible region. The instrument switches between each light source during data collection. The beams generated by the lamp would travel through a grating monochromator, so that a single wavelength was always emitted and changed to subsequent wavelengths during an experiment. This single wavelength would enter the beam splitter, sending one beam through a reference cuvette, containing a blank solvent matrix. The second beam passes through the sample cuvette, containing the sample of interest in the same solvent matrix. A certain amount of radiation would be absorbed by the sample, after which the remaining transmittance would be detected, and sent 
to the computer, for analysis by the software. ${ }^{9}$ While this UV/Vis instrument would be capable of following slow kinetics, for rapid kinetics, a different technique would have to be used.

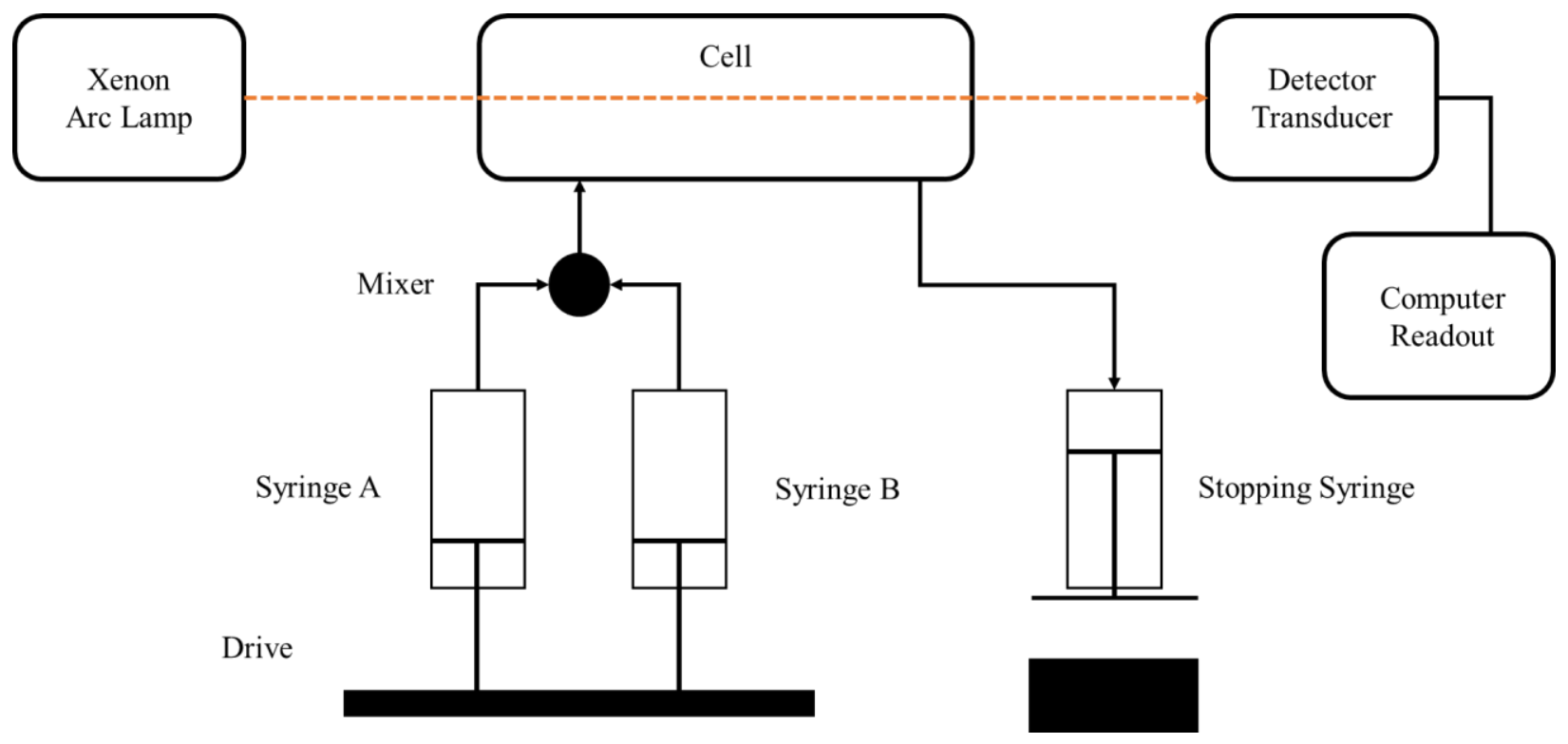

Figure 3. Single mixing stopped flow instrument

As shown in Figure 3, in order to follow fast reactions, a single mixed stopped-

flow UV/Vis instrument would have to be used. This instrument consists of two injection syringes, A and B, allowing the operator to inject a small volume of reactants which is limited by the stopping syringe. Upon leaving the syringes, the reactants enter an efficient mixer and cell. The cell is kept at a constant temperature of 25 degrees Celsius, and, since the size of the cell is fixed, the path length never changes. ${ }^{10}$ Beer's Law would be used to determine the concentration of different species inside the cell, at a wavelength of interest, set by the operator.

$$
A=\varepsilon b C
$$

Equation 1 shows Beer's Law, where $A$ is the absorbance of the contents of the cell, $\varepsilon$ the extinction coefficient of the species of interest at a particular wavelength, $b$ the pathlength determined by the size of the cell, and $C$ the concentration of the species of interest.

While UV/Vis allows for the determination of the reaction kinetics, UV/Vis does not 
offer any information about the identities of the products after oxidation. Therefore, it is necessary to employ electron spray ionization mass spectrometry (ESI-MS) to identify the products of the oxidation of ethionamide.

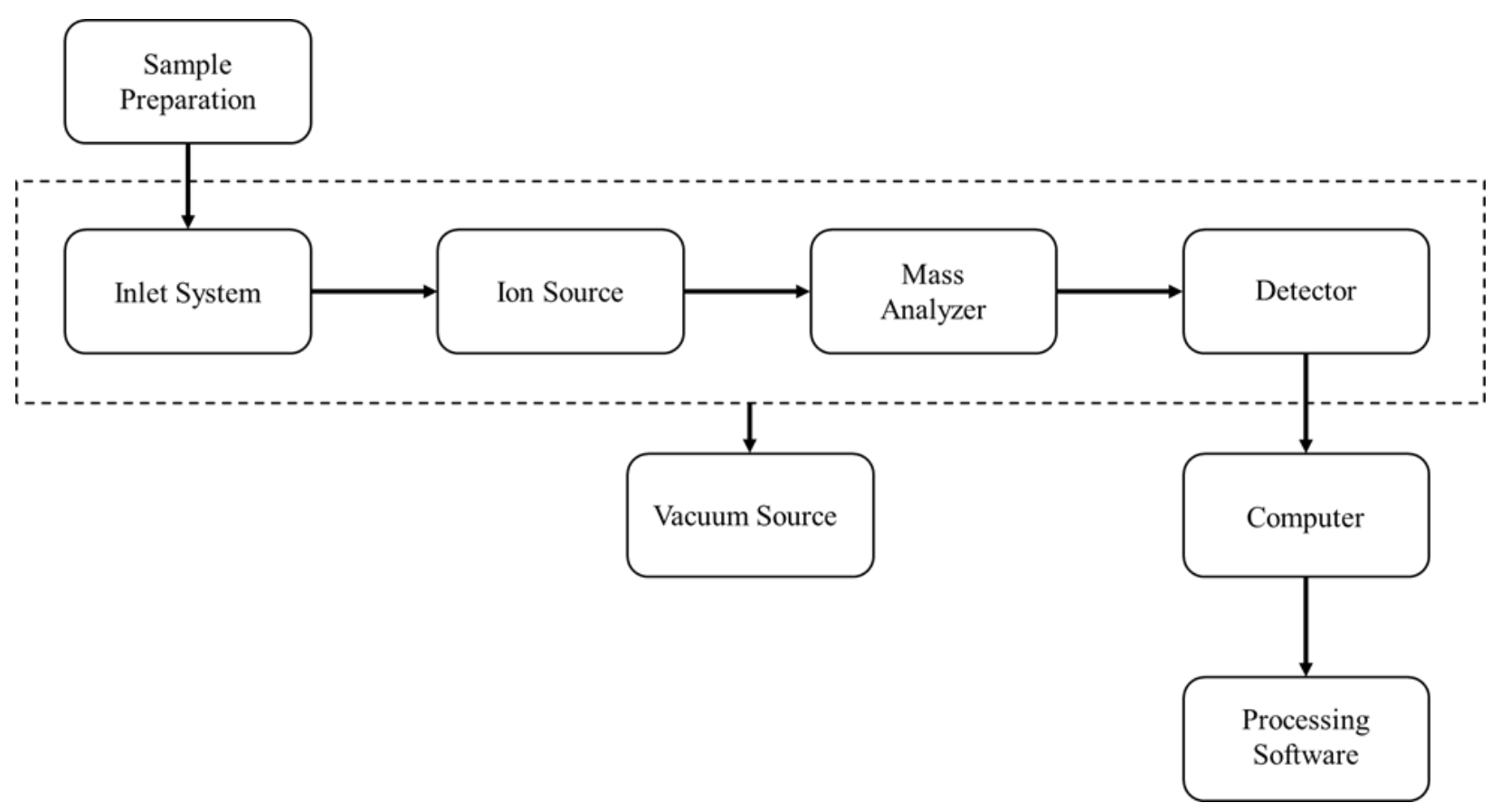

Figure 4. Block diagram of mass spectrometer

Figure 4 shows the components of the mass spectrometer: a sample is prepared via dilution into a solvent, after which it is injected into the inlet system, where it is carried via vacuum into the ion source. The sample is then ionized in the ion source, which leads to fragmentation. The mass analyzer accelerates and sorts the ionized sample particles, before sending them to the detector. The detector sends a signal specific to the mass to charge ratio, to the computer. The analyzing software enables the user to identify the mass to charge ratio $(\mathrm{m} / \mathrm{z})$ peaks. ${ }^{11}$ 


\section{EXPERIMENTAL PROCEDURES}

Materials. The following reagent grade chemicals were used without further purification: ethionamide, barium chloride (Arcos), sodium chloride, perchloric acid, 60-72 wt \%, peracetic acid, 32 wt \% (Fischer).

Methods. Fast reactions such as the formation of the sulfoxide, following the oxidation of ethionamide by peracetic acid, were monitored using a Hi-Tech Scientific SF61 single-mixing stopped flow spectrophotometer. Slower reactions such as the decomposition of the ethionamide sulfoxide product were followed using a Perkin-Elmer Lambda 25 UV/Vis spectrophotometer. All kinetics experiments were performed at $25.0+/-0.5^{\circ} \mathrm{C}$ and an ionic strength of $1.0 \mathrm{M}$ $(\mathrm{NaCl})$.

Water solutions for reactions were purified using a Barnstead Sybron Corp. water purification unit capable of producing both distilled and deionized water (Nanopure). ICP-MS was used to evaluate the concentrations of metal ions in the reagent water. Results from ICP-MS showed negligible amounts $(<0.1 \mathrm{ppb})$ of copper, iron and silver ions with approximately $1.5 \mathrm{ppb}$ of cadmium and $0.43 \mathrm{ppb}$ in lead as the highest metal ion concentrations.

A ThermoScientific LTQ-Orbitrap Discovery high resolution mass spectrometer with a dedicated Accela HPLC system was used to identify the products of the decomposition of the ethionamide sulfoxide product. The ESI-MS source parameters were set as follows: spray voltage $(\mathrm{kV}), 2.5$ in negative mode and 4.5 in positive mode; spray current $(\mu \mathrm{A}), 1.96$; sheath gas flow rate, 20; auxiliary gas flow rate, 0.01 ; capillary voltage $(\mathrm{V}),-16$; capillary temperature $\left({ }^{\circ} \mathrm{C}\right), 300$; and tube lens $(\mathrm{V}),-115$. Detection was carried out in both the negative ionization 
mode and positive (-ESI). The detection parameters were set up as follows: Analyzer; FTMS, positive and negative polarity; mass range; normal, resolution; 30 000, scan type; centroid.

Ethionamide is sparingly soluble in water, however, adding acid increased its solubility. 0.1 M perchloric acid was added to ethionamide at $0.01 \mathrm{M}$, which was then serial diluted with water to the desired concentration.

\section{RESULTS}

Reaction Overview. Scheme 1 showed a general overview of the oxidation of ethionamide by peracetic acid. Ethionamide was oxidized rapidly to ethionamide sulfoxide, after which it was oxidized further to the final product, 2-ethylisonicotinamide.

Scheme 1. General reaction overview

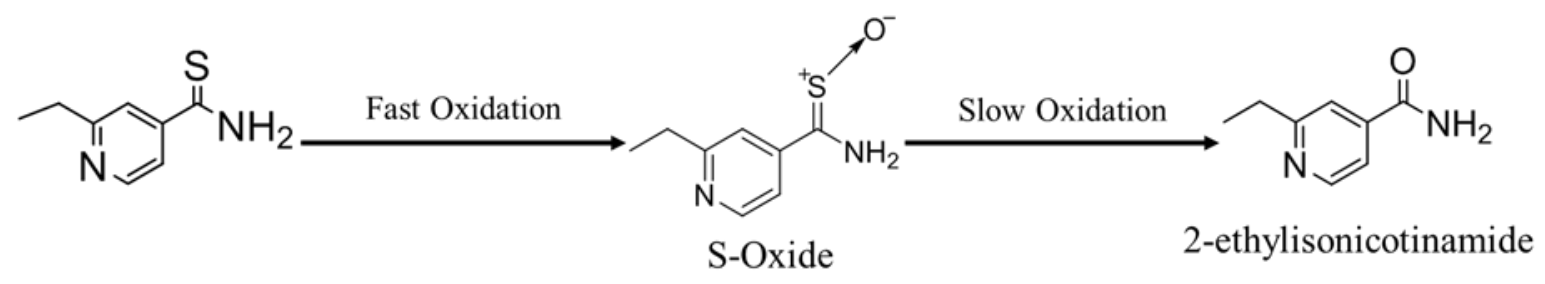

\section{Reaction Dynamics.}




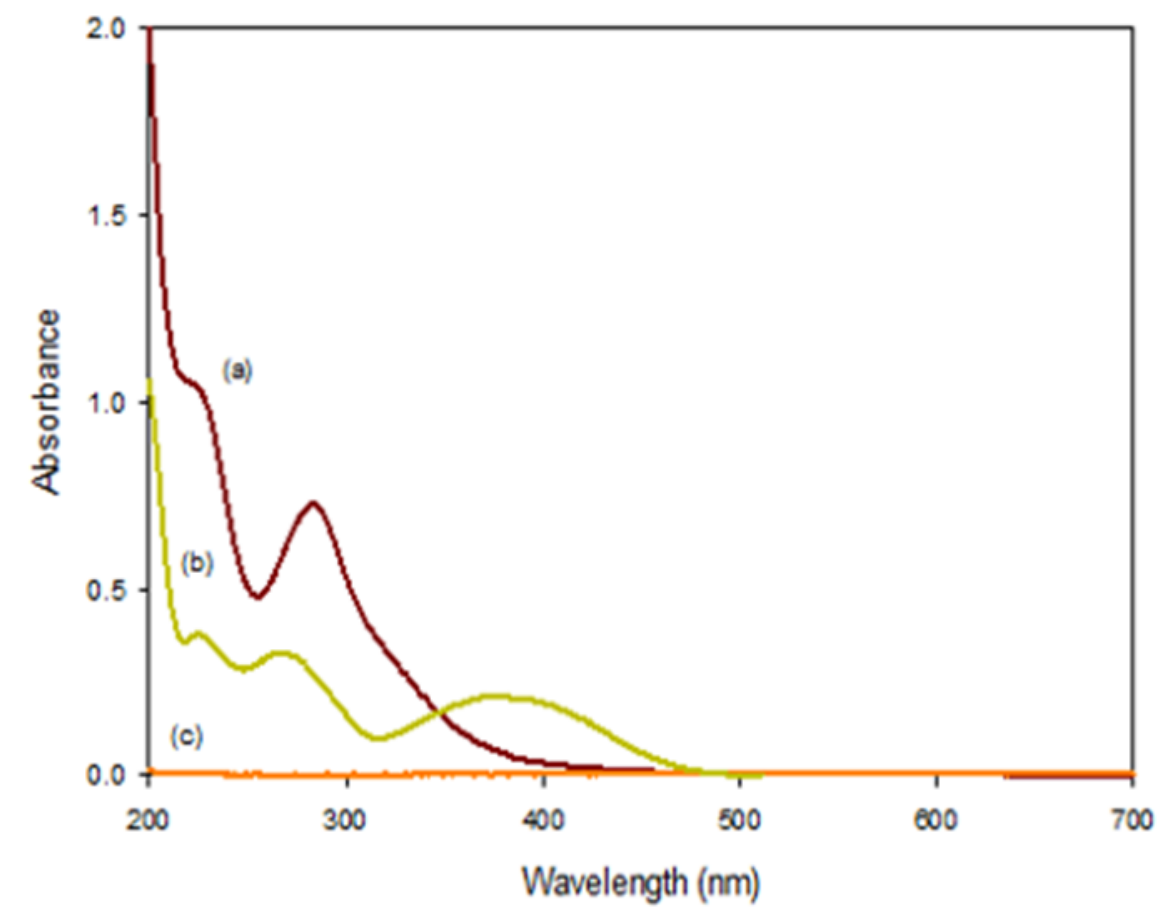

Figure 5. Spectra of (a) ETD, (b) ETD-SO, (c) Peracetic Acid (a) $[\mathrm{ETD}]=1.0 \times 10^{-4} \mathrm{M}$, (b) $[\mathrm{ETD}]=1.0 \times 10^{-4} \mathrm{M}$, (c) $\left[\mathrm{CH}_{3} \mathrm{CO}_{3} \mathrm{H}\right]$ $=1.0 \times 10^{-5} \mathrm{M}$

Peracetic acid is a mild oxidizer but readily oxidized ethionamide to ethionamide sulfoxide, mimicking the function of a monooxygenase, as seen in Reaction $1^{12}$ :

As seen in Figure 5, ethionamide showed intense absorption around $280 \mathrm{~nm}$, while the absorption of ethionamide sulfoxide was less at $280 \mathrm{~nm}$, with a shift in intensity to $250 \mathrm{~nm}$. The ethionamide sulfoxide showed an absorbance at $380 \mathrm{~nm}$, while the absorbance of ethionamide at that wavelength was small. The $380 \mathrm{~nm}$ wavelength was chosen to follow and determine the fast reaction kinetics, taking into account the absorbance of ethionamide at that wavelength. Peracetic acid, seen in trace (c) of Figure 5, showed no absorbance in the UV/Vis region and thus did not 
interfere with any UV/Vis measurements. However, since both ethionamide and ethionamide sulfoxide absorb at $380 \mathrm{~nm}$, extinction coefficients were determined for each species.

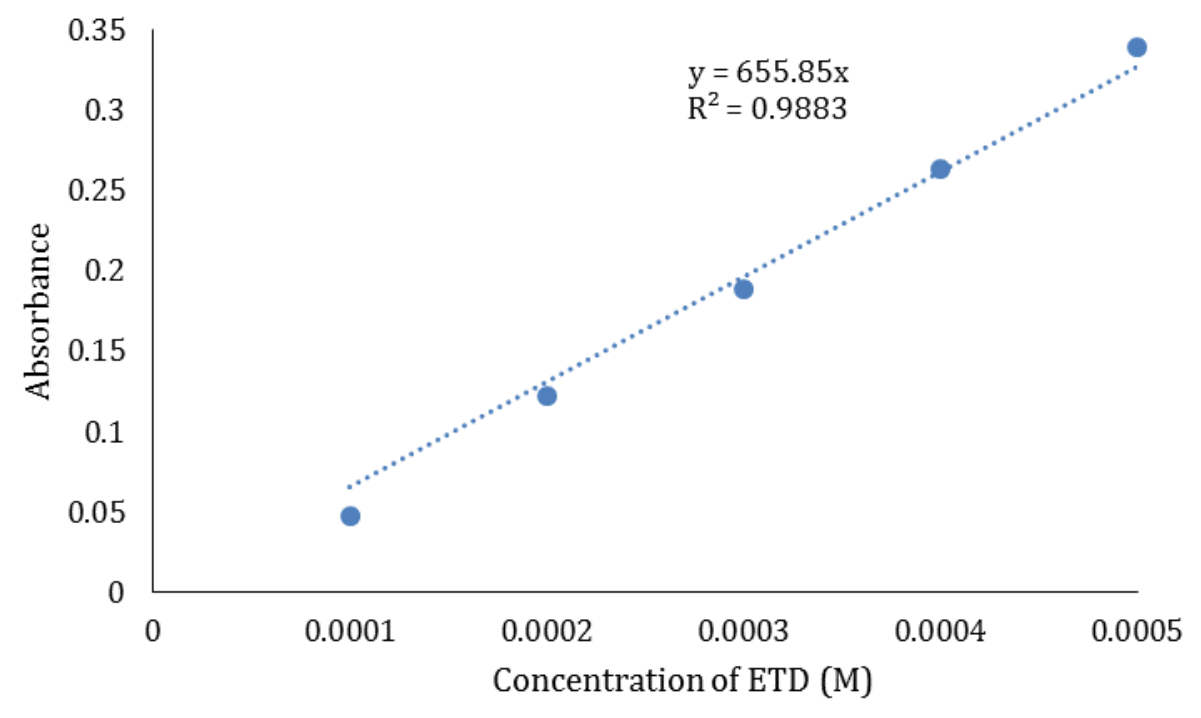

Figure 6. Extinction coefficient for ethionamide

Figure 6 shows how the extinction coefficient for ethionamide was calculated. Linear regression performed on the data set showed a slope, which was equal to the extinction coefficient, in this case $656 \mathrm{M}^{-1} \mathrm{~cm}^{-1}$. Similarly, the extinction coefficient for ethionamide sulfoxide was then found to be equal to $4737 \mathrm{M}^{-1} \mathrm{~cm}^{-1}$.

In excess oxidant, ethionamide sulfoxide was further oxidized to a sulfinic acid, as seen in Reaction 2:

$2 \mathrm{CH}_{3} \mathrm{CO}_{3} \mathrm{H}+\mathrm{CH}_{3} \mathrm{CH}_{2}\left(\mathrm{C}_{5} \mathrm{H}_{5} \mathrm{~N}\right) \mathrm{C}(=\mathrm{S}) \mathrm{NH}_{2} \rightarrow \mathrm{CH}_{3} \mathrm{CH}_{2}\left(\mathrm{C}_{5} \mathrm{H}_{5} \mathrm{~N}\right) \mathrm{C}(=\mathrm{NH}) \mathrm{SO}_{2} \mathrm{H}+2 \mathrm{CH}_{3} \mathrm{COOH}$ (R2) 


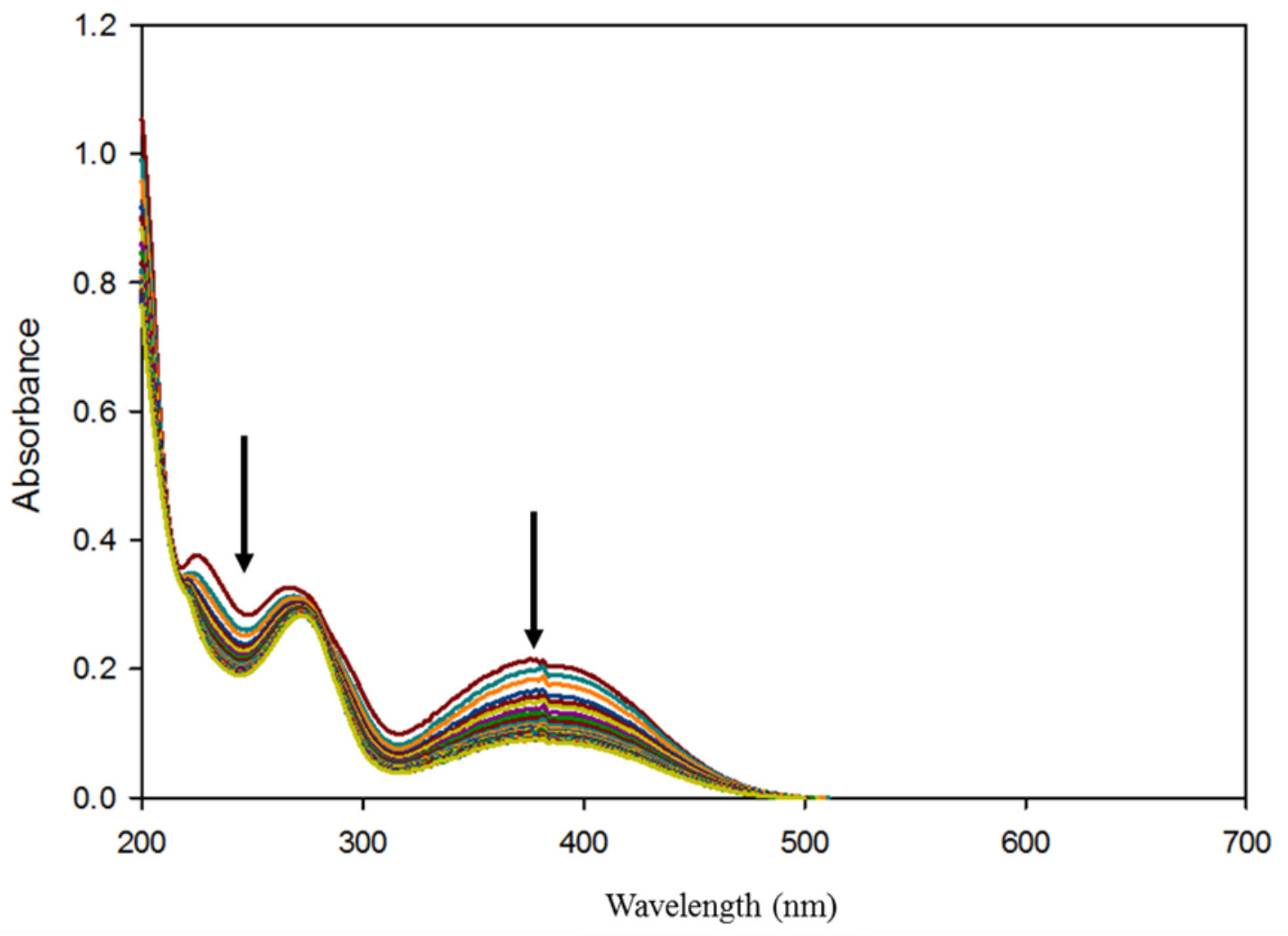

Figure 7. $[\mathrm{ETD}]=1.0 \times 10-4 \mathrm{M},\left[\mathrm{CH}_{3} \mathrm{CO}_{3} \mathrm{H}\right]=0.005 \mathrm{M}$, spectra shown at 2 minute intervals, total time elapsed $=20$ minutes

Figure 7 showed the second part of the reaction, the decomposition of ethionamide sulfoxide to 2-ethylisonicotinamide. In this, the product of initial oxidation, ethionamide sulfoxide decomposes slowly over time, spectra were taken every 2 minutes over a total time period of 20 minutes. Depending on the initial concentrations of reactants, the decomposition took up to an hour, illustrating that the second oxidation occurred at a slow rate, which is illustrated in Figure 8, below. 


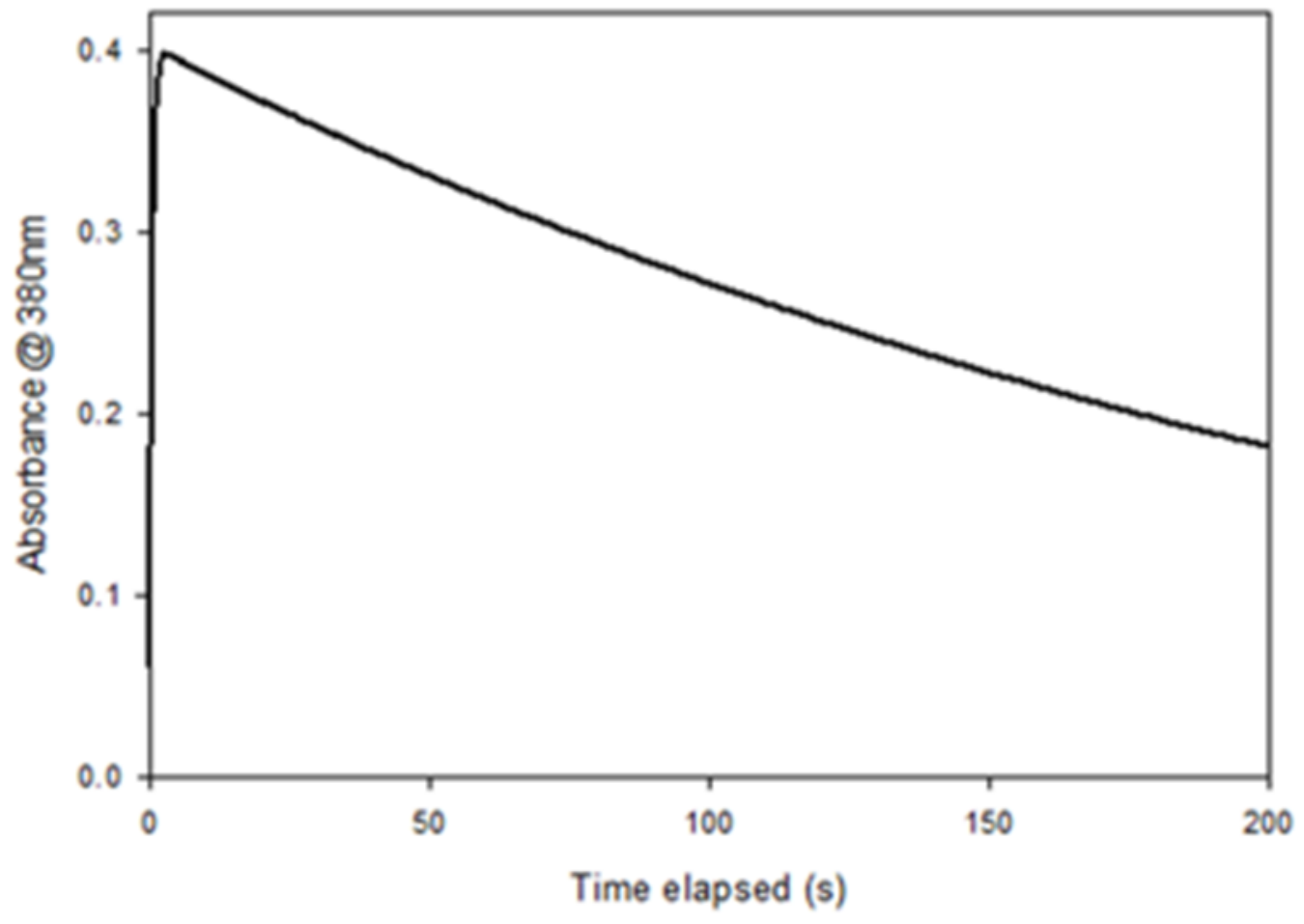

Figure 8. Decomposition of ETD-SO over $200 \mathrm{~s}$. $[\mathrm{ETD}]=1.0 \times 10-4 \mathrm{M},\left[\mathrm{CH}_{3} \mathrm{CO}_{3} \mathrm{H}\right]=0.005 \mathrm{M}$

As seen in Figure 8, data from the stopped-flow UV/Vis instrument showed a biphasic reaction, with a rapid initial oxidation of ethionamide, which took less than 10 seconds. This was followed by the slow decomposition of the ethionamide sulfoxide product, to 2ethylisonicotinamide, which was the byproduct of further oxidation. However, absorbance at time $0 \mathrm{~s}$ was not equal to zero, due to the absorbance of the ethionamide present prior to the start of the reaction. The increase in absorption was rapid, as the initial product ethionamide sulfoxide, had a much larger extinction coefficient at $380 \mathrm{~nm}$ than the reactant ethionamide. 


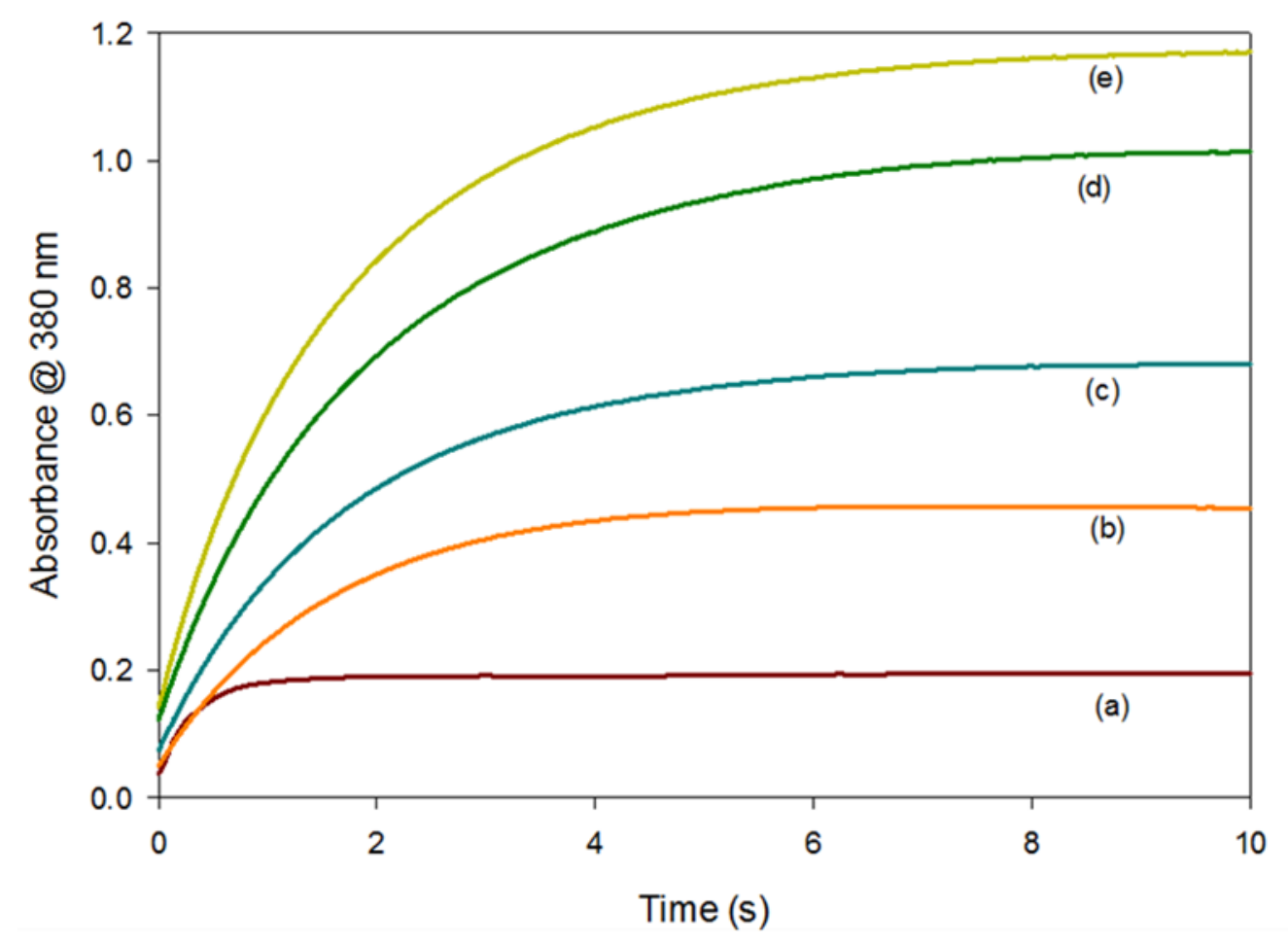

Figure 9. Variation of ETD in its oxidation by per acetic acid showing total absorbance at $380 \mathrm{~nm}$. $\left[\mathrm{CH}_{3} \mathrm{CO}_{3} \mathrm{H}\right]=0.005 \mathrm{M}$, $[\mathrm{H}+]$ $=1.0 \times 10^{-4} \mathrm{M}, \mathrm{I}_{\mathrm{NaCl}}=1.0 \mathrm{M}$; and varied $[\mathrm{ETD}](\mathrm{a})=5.0 \times 10^{-5} \mathrm{M}$, (b) $1.0 \times 10^{-4} \mathrm{M}$, (c) $1.5 \times 10^{-4} \mathrm{M}$, (d) $2.0 \times 10^{-4} \mathrm{M}$, (e) $2.5 \times 10^{-4}$ M

Figure 9 shows the reaction rate as the concentration of ethionamide was varied; the initial part of the reaction, the oxidation of ethionamide to ethionamide sulfoxide was complete within 10 seconds. These spectra consisted of the combination of the absorbances of ethionamide and ethionamide sulfoxide. Therefore, in order to determine the rate of reaction this information needed to be split into two parts, the consumption of ethionamide and the formation of ethionamide sulfoxide. Using Equation 1, at any given time, the total absorption, $A$, was the sum of the following,

$$
A=\left(\varepsilon_{E T D}[E T D]+\varepsilon_{E T D-s o}[E T D-S O]\right) b
$$

where the path length, $b$, was equal to $1 \mathrm{~cm} \cdot{ }^{13}$ Using mass balance, a simple relationship could be found to the initial concentration of ethionamide,

$$
[E T D]_{0}=[E T D]+[E T D-S O]
$$


after which the following differential equation could be written,

$$
\frac{d A}{d t}=\frac{\left([E T D]\left(\varepsilon_{E T D}-\varepsilon_{E T D-S O}\right)+\varepsilon_{E T D-S O}[E T D]_{0}\right.}{d t}
$$

where $[E T D]$ was the instantaneous concentration at any given time, $t$. Equation 4 was then integrated and solved for the instantaneous concentration, resulting in

$$
[E T D]_{t}=\frac{A_{t}-\varepsilon_{E T D-S O}[E T D]_{0}}{\varepsilon_{E T D}-\varepsilon_{E T D-S O}}
$$

Equation 5 could then be used in a spreadsheet to calculate the concentration of ethionamide at any time, $t$.

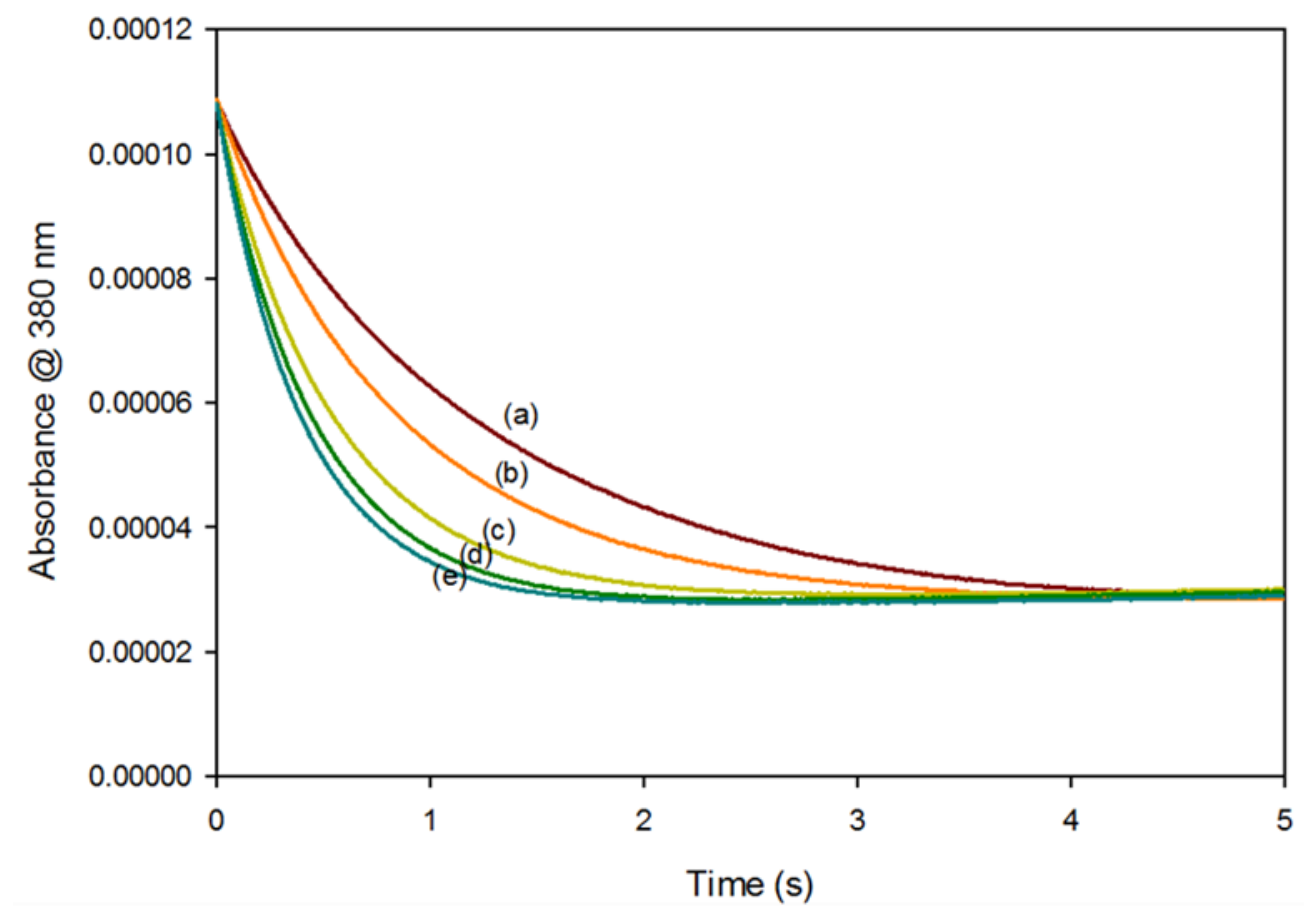

Figure 10. Concentration variations of ETD in its oxidation by peracetic acid showing consumption of ETD at $380 \mathrm{~nm}$. Conditions were the same as in Figure 9.

Figure 10 then showed the consumption of ethionamide as the reaction proceeded. The conditions were the same as Figure 9 and Equation 5 was used to calculate the absorbance value of ethionamide at each data point. To calculate the rate constant, the initial rate was set equal to $k$, resulting in Equation 6: 


$$
v=k\left[\text { PaAcid }_{0}\right]([E T D]-x)
$$

where $v$ was the reaction velocity, $[$ PaAcid 0$]$ the initial concentration of peracetic acid, $[E T D]$ the concentration of ethionamide, and $x$ the amount of ethionamide that reacted. When taken at the initial point of the curve, this was less than $1 \%$ of the total concentration of ethionamide. Since peracetic acid was in excess, $[\mathrm{PaAcid}]$ > [ETD], which meant an apparent rate constant was determined using Equation 7,

$$
k_{a p p}=k\left[\text { PaAcid }_{0}\right]
$$

where $k_{a p p}$ was the pseudo first order rate constant, which allowed for the calculation of the true rate constant, $k$, by dividing the pseudo first order rate constant by the initial concentration of peracetic acid. When plotting the initial slope of each trace found in Figure 10 versus the ethionamide concentration, a linear relationship was found where the slope, $m$, was equal to $k_{\text {app }}$. The true rate constant, $k$, was then calculated as $3.08 \pm 0.72 \times 10^{2} \mathrm{M}^{-1} \mathrm{~s}^{-1}$. 


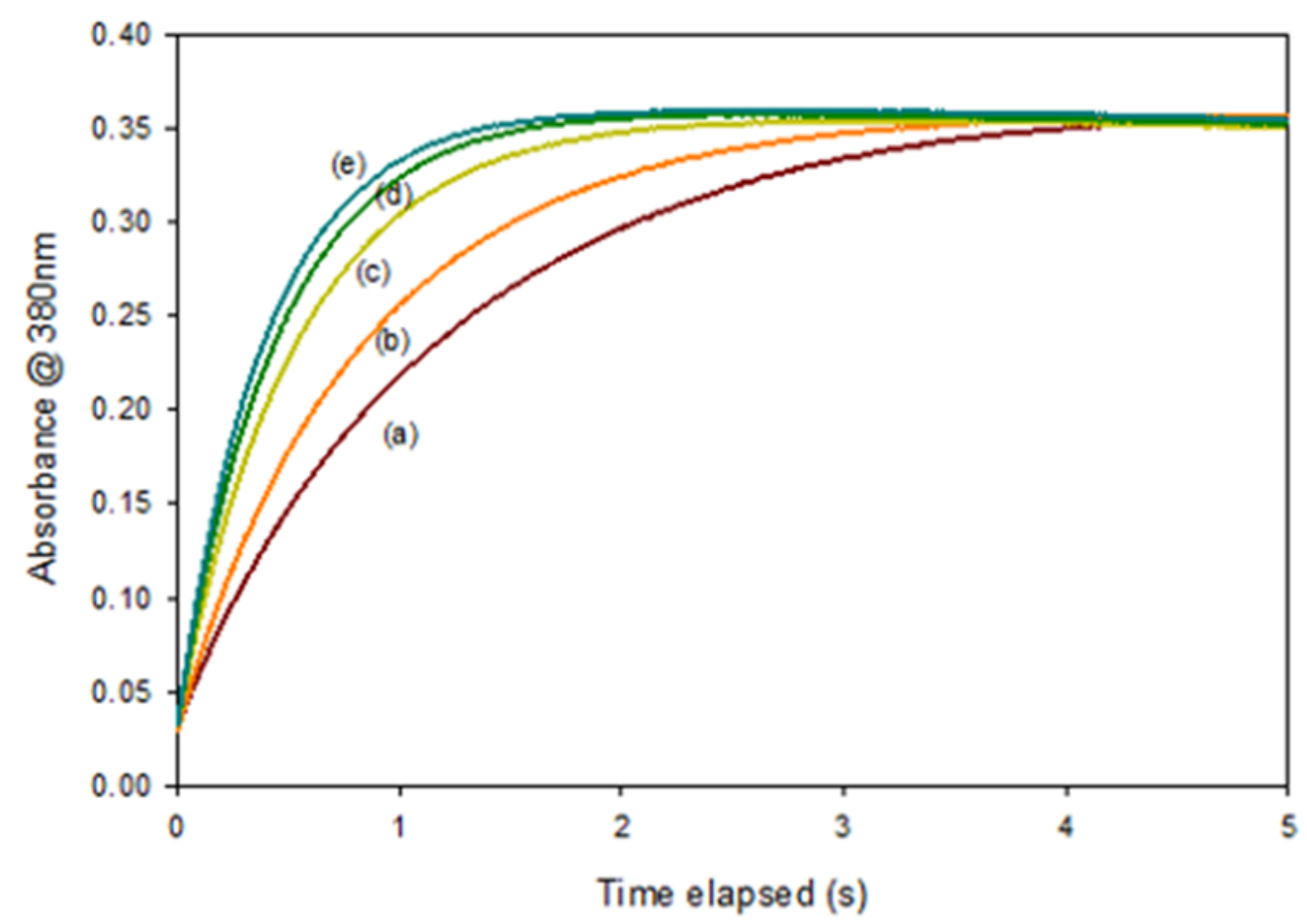

Figure 11. Variation of peracetic acid concentration $[\mathrm{ETD}]=1.0 \times 10-4 \mathrm{M}$, and varied $\left[\mathrm{CH}_{3} \mathrm{CO}_{3} \mathrm{H}\right]$ (a) $0.0020 \mathrm{M}$, (b) $0.0030 \mathrm{M}$, (c) $0.0045 \mathrm{M}$, (d) $0.0055 \mathrm{M}$, (e) $0.0065 \mathrm{M}$

Figure 11 shows the reaction at a constant concentration of ethionamide, with increasing concentrations of peracetic acid. Here the limiting reagent was ethionamide, as the concentration of ethionamide sulfoxide did not vary when the concentration of peracetic acid was increased. Peracetic acid was always kept in excess. As seen in Figure 11, as the concentration of peracetic acid was increased, the initial rate of the reaction increased as well. The traces mimic those seen in Figure 7, indicating that similar kinetics were observed. In excess peractic acid, first order kinetics were observed and a stoichiometry of 1:1 was thus quickly attained. 


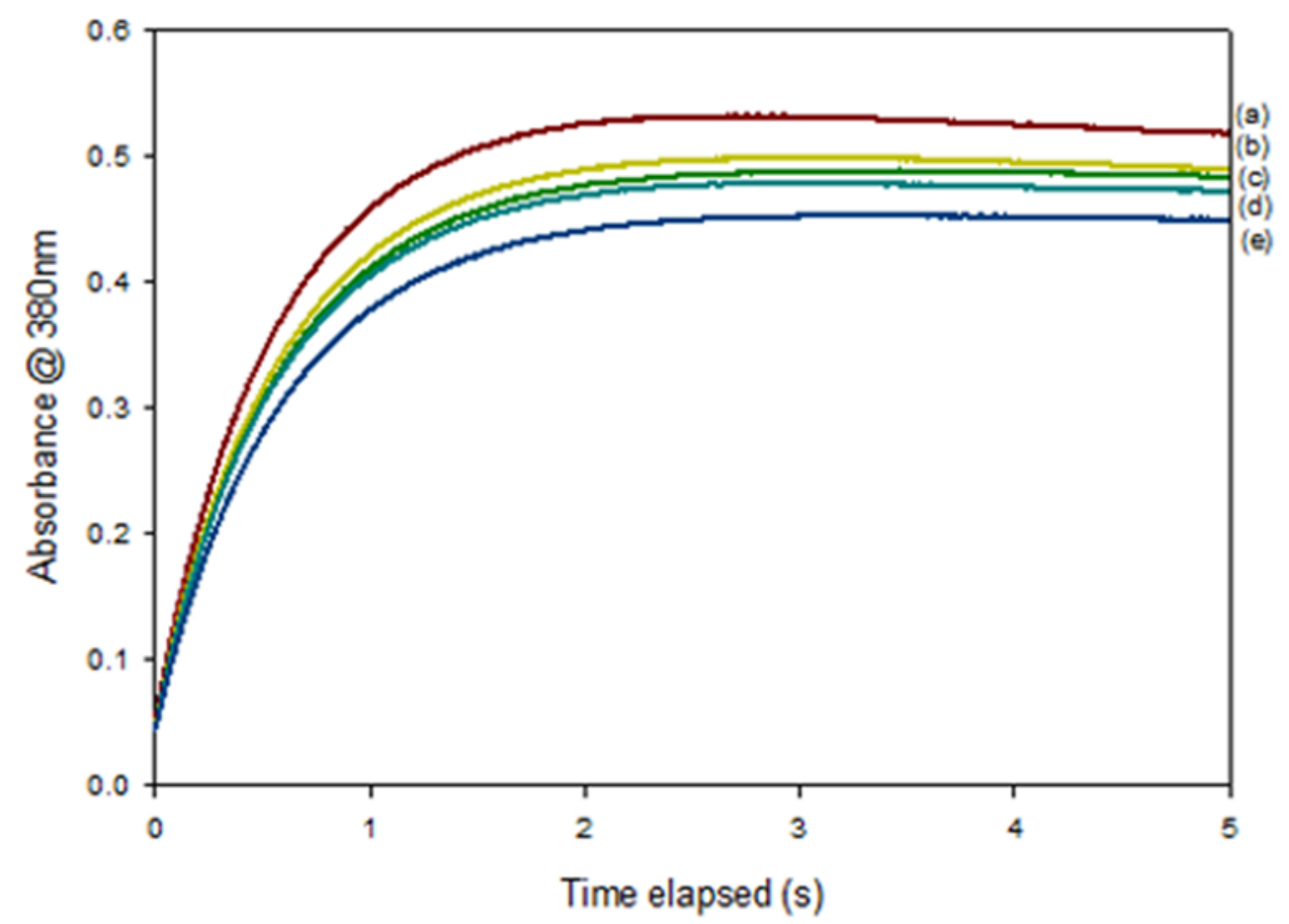

Figure 12. Variation of perchloric acid concentration $[E T D]=1.0 \times 10-4 \mathrm{M},\left[\mathrm{CH}_{3} \mathrm{CO}_{3} \mathrm{H}\right]=0.005 \mathrm{M}\left[\mathrm{HClO}_{4}\right]$ (a) $0.10 \mathrm{M}$, (b) 0.25 $\mathrm{M}$, (c) $0.50 \mathrm{M}$, (d) $0.75 \mathrm{M}$, (e) $1.00 \mathrm{M}$

An increase in acid concentration acted as an inhibitor of the oxidation of ethionamide (Figure 12). Ethionamide had several possible points of protonation, with the sulfur serving as an excellent proton acceptor. As the acid concentration was increased, so was the protonation state of the sulfur center, which reduced the nucleophilicity, and thus the electrophilic attack of oxygen from peracetic acid was less likely. The resulting molecule would then also be resonance stabilized, as indicated in Scheme 2, below.

Scheme 2. Protonation scheme

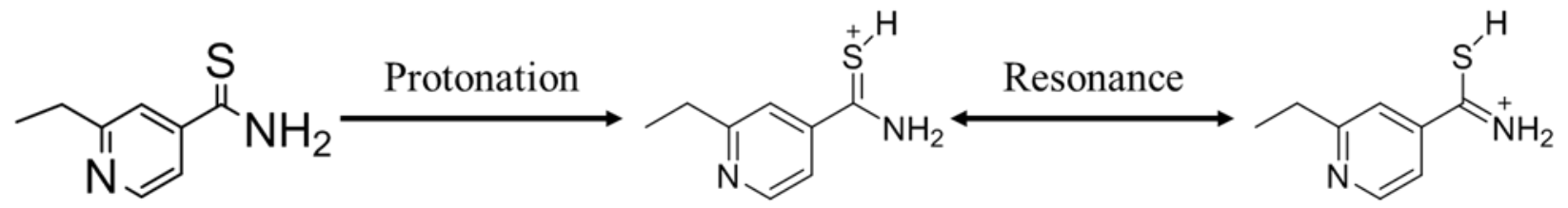

Ethionamide 


\section{Product Identification.}

The following mass spectra were obtained in positive mode, unless stated otherwise.

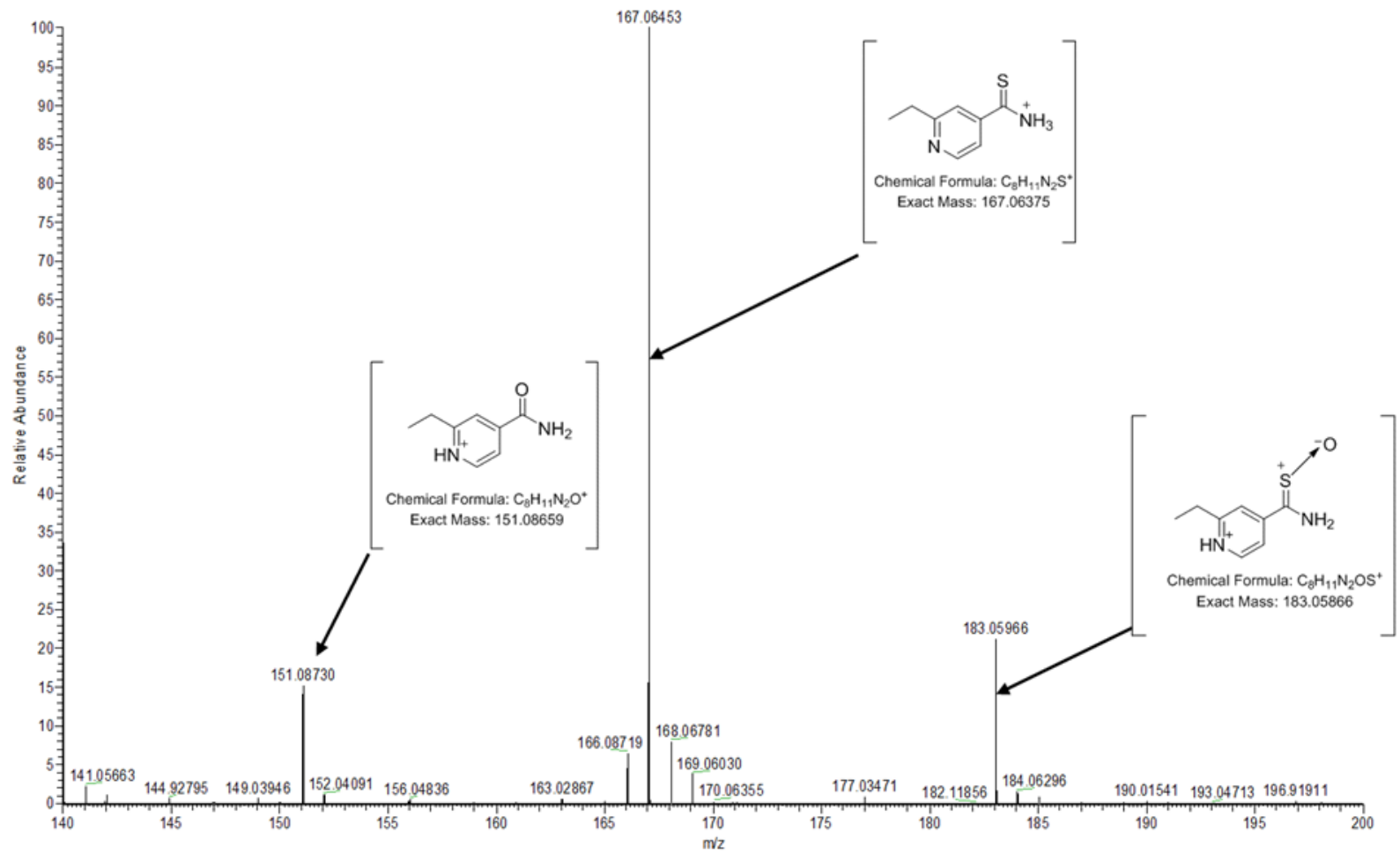

Figure 13. $[E T D]=3.0 \times 10^{-4} \mathrm{M},\left[\mathrm{CH}_{3} \mathrm{CO}_{3} \mathrm{H}\right]=3.0 \times 10^{-4} \mathrm{M}$

At a ratio of 1:1 ethionamide to peracetic acid, in Figure 13, both ethionamide sulfoxide and 2-ethylisonicotinamide were observed after the reaction went to completion. As expected, a significant concentration of ethionamide remained, due to the concentration of perchloric acid present. 


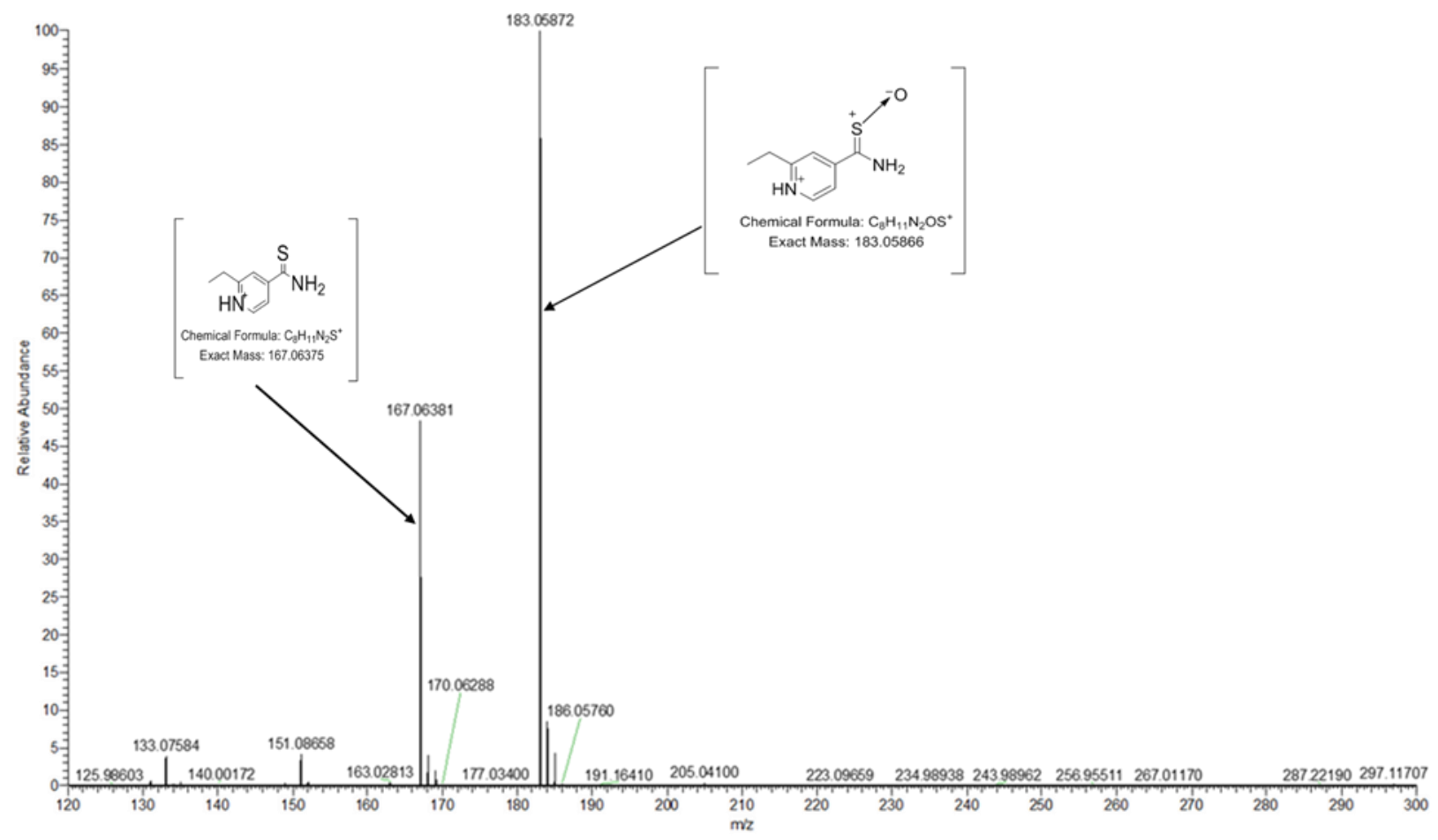

Figure 14. $[E T D]=3.0 \times 10^{-4} \mathrm{M},\left[\mathrm{CH}_{3} \mathrm{CO}_{3} \mathrm{H}\right]=9.0 \times 10^{-4} \mathrm{M}$

At a ratio of 1:3 ethionamide to peracetic acid, before the reaction went to completion, the major product was ethionamide sulfoxide. Little of the 2-ethylisonicotinamide product, at an $\mathrm{m} / \mathrm{z}=151.08658$, was formed at this time, seen in Figure 14. 


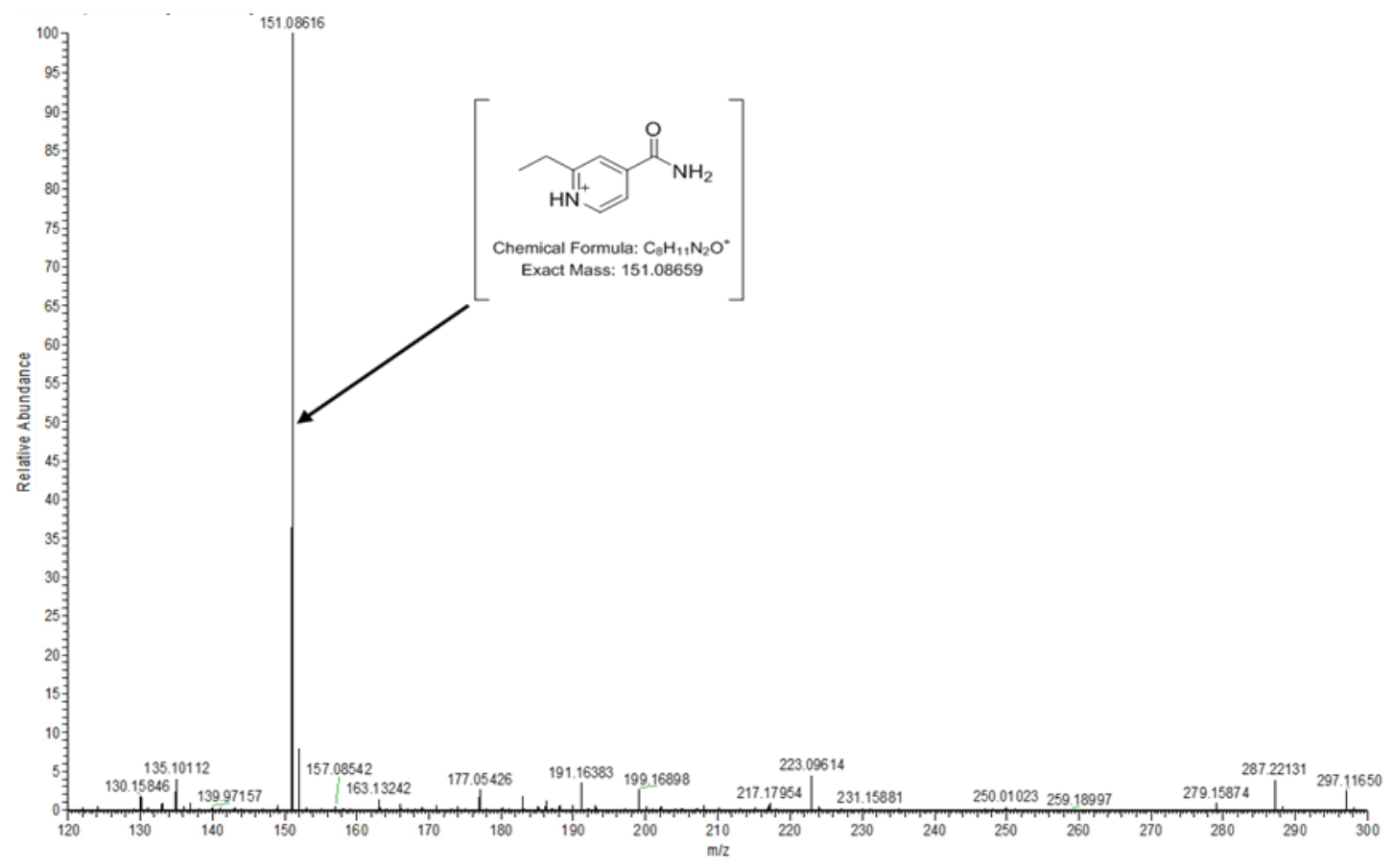

Figure 15. $[E T D]=3.0 \times 10^{-4} \mathrm{M},\left[\mathrm{CH}_{3} \mathrm{CO}_{3} \mathrm{H}\right]=1.5 \times 10^{-3} \mathrm{M}$. Spectrum acquired 30 minutes into the reaction

As seen in Figure 15, after flooding the reaction with peracetic acid to ensure the complete consumption of all ethionamide present, the only remaining product was 2-

ethylisonicotinamide, at an $\mathrm{m} / \mathrm{z}=151.08658$.

\section{Oxidation Mechanism.}

The initial oxidation yielded a sulfenic acid, which stabilized via tautomerization to the zwitterionic sulfoxide, which was isolated using ESI-MS. The reaction scheme was illustrated in Scheme 3, below.

Scheme 3. Initial oxidation scheme<smiles>CCc1cc(C(N)=S)ccn1</smiles> 


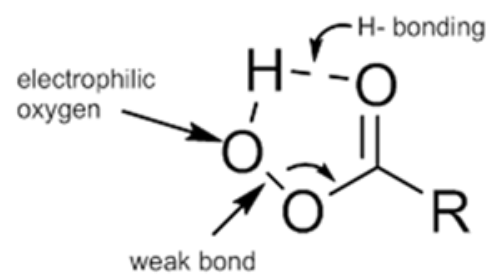

Figure 16. Structure of peracetic acid
Peracetic acid, shown in Figure 16, is a weak acid and classified as an organic peroxide, rendering it suitable as an

molecule. This bond is weak because of the potential of hydrogen bonding between the acidic proton and the carbonyl group of the carboxylic acid, creating an electrophilic oxygen which can potentially add to a nucleophile.

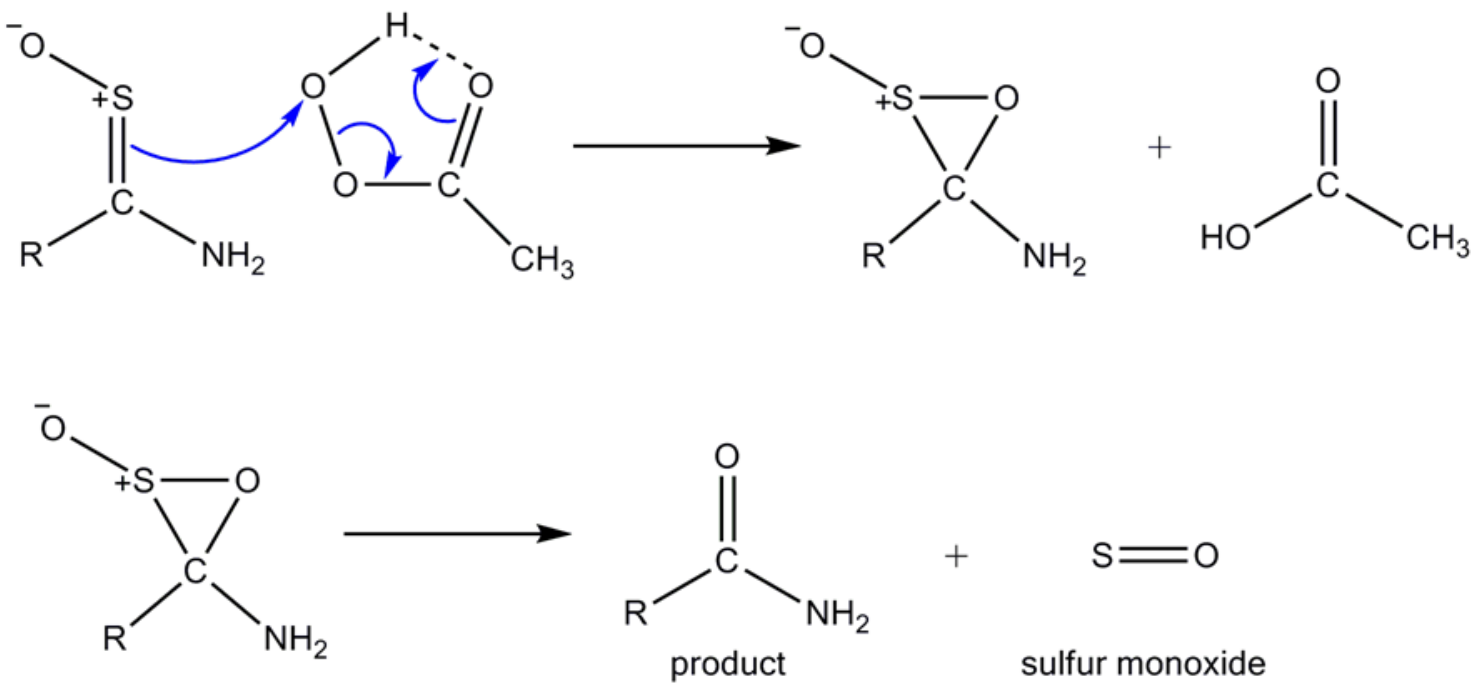

Figure 17. Sulfoxide oxidation pathway

The oxidation of the thioamide bond by peracetic acid leads to the formation of the sulfoxide. This oxidation occurs via epoxidation followed by hydrolysis and rearrangement from the sulfenic acid to the sulfoxide. ${ }^{8}$ The zwitterionic form of the sulfinic acid, shown in Figure 17, was susceptible to cleavage of the carbon-sulfur bond, which released a sulfoxyl anion radical that dimerized to form dithionite. ${ }^{14}$ Dithionite is easily oxidized to sulfate, however, the formation of sulfate was not observed. A sulfate test performed using barium chloride gave negative results. This showed that sulfur monoxide was acting as the leaving group, leading to the cleavage of the carbon-sulfur bond, illustrated in Figure 17. While sulfur monoxide was 
unstable, it was previously formed and detected in the activation of a frustrated Lewis pair of $\mathrm{N}$ sulfinyamine. $^{15}$

Therefore, mass spectra were obtained in negative mode to find the sulfur species which was located as dimeric sulfur monoxide. Since peracetic acid is a weak oxidizer, it was unable to further oxidize sulfur monoxide or its dimer.

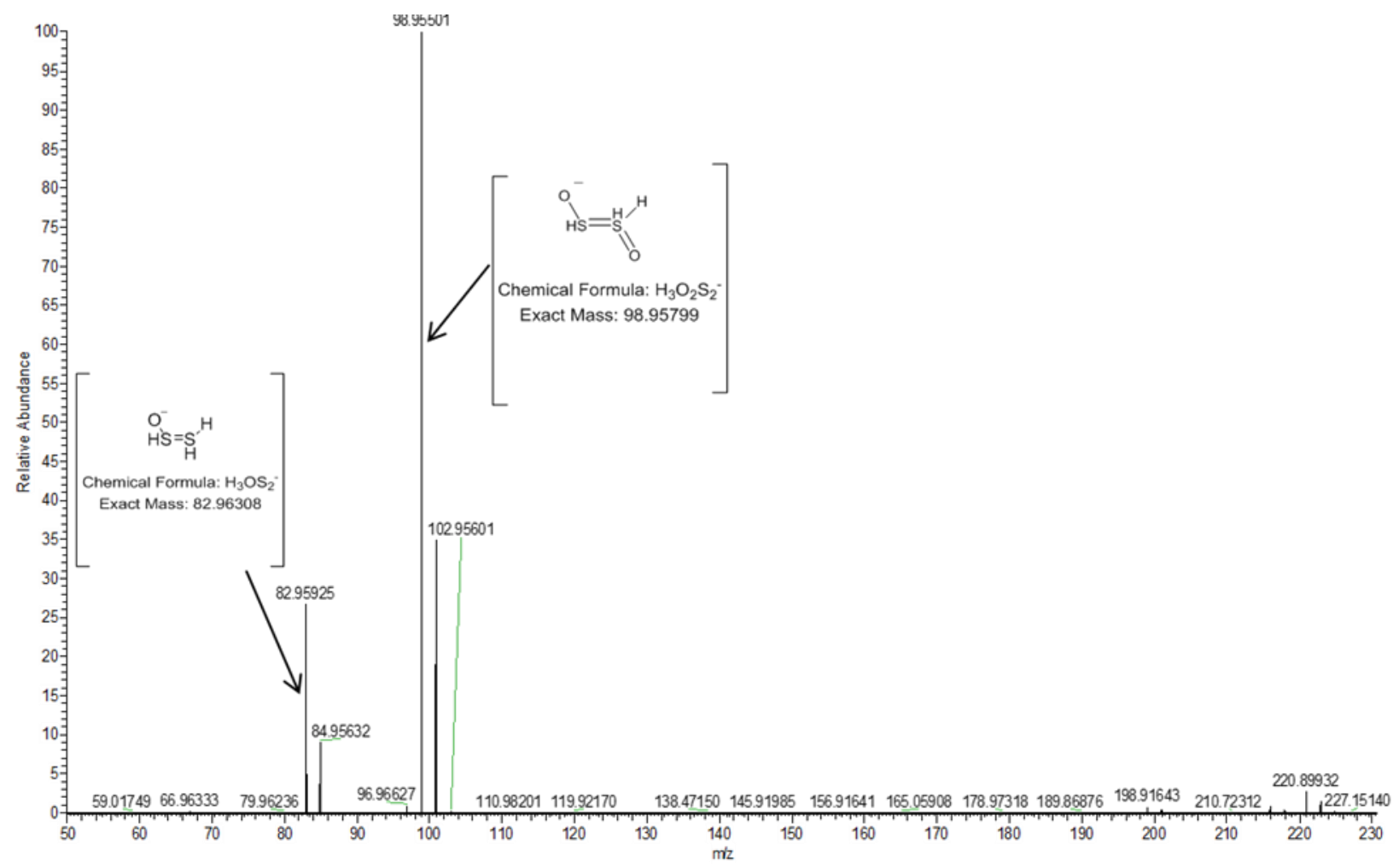

Figure 18. Mass spectrum focusing on the sulfur species

The mass spectrum seen in Figure 18 shows a peak at $\mathrm{m} / \mathrm{z}=98.95501$, indicating the dimerized sulfur monoxide species and a peak at $\mathrm{m} / \mathrm{z}=82.95925$, which was exactly sixteen mass units, or one oxygen atom less than the peak for the dimerized species. However, the dimerized species was the most abundant. 


\section{CONCLUSION}

Peracetic acid successfully oxidized ethionamide, mimicking metabolism by Mycobacterium tuberculosis to produce ethionamide sulfoxide. Ethionamide sulfoxide was then further oxidized to yield 2-ethylisonicotinamide, through a diphasic process; the initial oxidation occurred rapidly followed by the oxidation of the slow second phase. The second phase resulted in the loss of the thioamide functional group, oxidized to an amide. The leaving group was determined as sulfur monoxide, which dimerized in solution, and no sulfates were formed.

\section{Acknowledgements.}

A thank you to Dr. Simoyi for offering this lab opportunity, to Kudzanai Chipiso and Matthew Eskew for helping in the design of the experiments and the evaluation of the results.

\section{REFERENCES}

1. Vipin, P. V., \& Solanke, P. V. Prevalence Study of Tuberculosis Cases in Sree Mookambika Institute of Medical Science. International Journal of Contemporary Medicine, 4(1), 7-9. (2016).

2. Centers for Disease Control and Prevention (CDC). (2012). Reported tuberculosis in the United States, 2010. Atlanta, GA: US Department of Health and Human Services, CDC; 2011.

3. Kumar V, Abbas AK, Fausto N, Mitchell RN Robbins Basic Pathology (8th ed.). Saunders Elsevier. pp. 516-522. ISBN 978-1-4160-2973-1. (2007). 
4. Baulard, A. R., Betts, J. C., Engohang-Ndong, J., Quan, S., McAdam, R. A., Brennan, P. J., ... \& Besra, G. S. Activation of the pro-drug ethionamide is regulated in mycobacteria. Journal of Biological Chemistry, 275(36), 28326-28331. (2000).

5. Vilchèze, C., Av-Gay, Y., Attarian, R., Liu, Z., Hazbón, M. H., Colangeli, R., ..., \& Jacobs Jr, W. R. Mycothiol biosynthesis is essential for ethionamide susceptibility in Mycobacterium tuberculosis. Molecular microbiology, 69(5), 1316-1329. (2008).

6. Agerton, T. B., Valway, S. E., Blinkhorn, R. J., Shilkret, K. L., Reves, R., Schluter, W. W., ... \& Onorato, I. M. Spread of strain W, a highly drug-resistant strain of Mycobacterium tuberculosis, across the United States. Clinical infectious diseases, 29(1), 85-92. (1999).

7. DeBarber, A. E., Mdluli, K., Bosman, M., Bekker, L. G., \& Barry, C. E. Ethionamide activation and sensitivity in multidrug-resistant Mycobacterium tuberculosis. Proceedings of the National Academy of Sciences, 97(17), 9677-9682. (2000).

8. Olojo, R., Simoyi, \& R., H. Oxyhalogen-Sulfur Chemistry: Kinetics and Mechanism of the Oxidation of Thionicotinamide by Peracetic Acid. Journal of Physical Chemistry A, 108(6), 1018-1023. (2004).

9. Perkin Elmer Lambda 25 Users Guide <http://people.bath.ac.uk/gp304/uv/PerkinElmer _Lambda35_manual_EN.pdf>

10. Stopped flow technique <http://www.hi-techsci.com/techniques/stoppedflow/>

11. Agilent 6100 Series Quadrupole LC/MS Systems Concepts Guide < http://www.agilent.com/cs/library/usermanuals/public/G1960-90079_6100_Concepts.pdf>

12. Awad, Mohamed Ismail; Denggerile, Ao; Ohsaka, Takeo "Electroreduction of Peroxyacetic Acid at Gold Electrode in Aqueous Media". Journal of the Electrochemical Society 151: E358. (2004). doi:10.1149/1.1812733 
13. 'KinetAsyst' Stopped-Flow Systems < http://www.hitechsci.com/products/stoppedflowsystem />

14. Aslabban, M.; Adigun, R. A.; DeBenedetti, W. J.; Mbiya, W.; Mhike, M.; Morakinyo, M. K.; Otoikhian, A. A.; Ruwona, T.; Simoyi, R. H. Detailed Mechanistic Studies into the Reactivities of Thiourea and Substituted Thiourea Oxo-Acids Part I: Decompositions and Hydrolyses of Dioxides in Basic Media. J. Phys. Chem. A. (2014).

15. Longobardi, L. E.; Wolter, V.; Stephan, D. W. Frustrated Lewis pair activation of an Nsulfinylamine: a source of sulfur monoxide. Angew. Chem. Int. Ed Engl. 54 (3), 809812. (2015). 